\title{
Immunoreactivity of the 14F7 Mab Raised against N-Glycolyl GM3 Ganglioside in Primary Lymphoid Tumors and Lymph Node Metastasis
}

\author{
Rancés Blanco, ${ }^{1}$ Damián Blanco, ${ }^{2}$ Yisel Quintana, ${ }^{1}$ Xiomara Escobar, ${ }^{2}$ \\ Charles E. Rengifo, ${ }^{3}$ Marta Osorio, ${ }^{4}$ Zailí Gutiérrez, ${ }^{5}$ Janet Lamadrid, ${ }^{5}$ Mercedes Cedeño, ${ }^{1}$ \\ Milagros Frómeta, ${ }^{1}$ Adriana Carr, ${ }^{6}$ and Enrique Rengifo ${ }^{1}$ \\ ${ }^{1}$ Laboratory of Recognition and Biological Activity Assays, Department of Quality Control, Center of Molecular Immunology, \\ P.O. Box 16040, 216 Street and 15 Avenue Atabey, Playa, 11600 Havana, Cuba \\ ${ }^{2}$ Department of Cell Biology and Tissues Banking, National Institute of Oncology and Radiobiology, 29 and F Street Vedado, \\ Plaza de la Revolución, 10400 Havana, Cuba \\ ${ }^{3}$ Department of Pathology, Manuel Fajardo General Hospital, Zapata and D Street Vedado, Plaza de la Revolución, \\ 10400 Havana, Cuba \\ ${ }^{4}$ Clinical Trials Unit, National Institute of Oncology and Radiobiology, 29 and F Street Vedado, Plaza de la Revolución, \\ 10400 Havana, Cuba \\ ${ }^{5}$ Department of Pathology, National Institute of Oncology and Radiobiology, 29 and F Street Vedado, Plaza de la Revolución, \\ 10400 Havana, Cuba \\ ${ }^{6}$ Research and Development Direction, Center of Molecular Immunology, P.O. Box 16040, 216 Street and 15 Avenue Atabey, \\ Playa, 11600 Havana, Cuba
}

Correspondence should be addressed to Rancés Blanco; rances@cim.sld.cu

Received 31 July 2013; Revised 30 September 2013; Accepted 10 October 2013

Academic Editor: Shahid Pervez

Copyright (c) 2013 Rancés Blanco et al. This is an open access article distributed under the Creative Commons Attribution License, which permits unrestricted use, distribution, and reproduction in any medium, provided the original work is properly cited.

\begin{abstract}
The reactivity of the 14F7 Mab, a highly specific IgG1 against N-glycolyl GM3 ganglioside (NeuGcGM3) in normal tissues, lymphomas, lymph node metastasis, and other metastatic sites was assessed by immunohistochemistry. In addition, the effect of chemical fixation on the 14F7 Mab staining using monolayers of P3X63Ag. 653 cells was also evaluated. Moreover, the ability of 14F7 to bind NeuGcGM3 ganglioside inducing complement-independent cytotoxicity by a flow cytometry-based assay was measured. The 14F7 Mab was reactive in unfixed, $4 \%$ paraformaldehyde, $4 \%$ formaldehyde, and acetone fixed cells. Postfixation with acetone did not alter the localization of NeuGcGM3, while the staining with 14F7 Mab was significantly eliminated in both cells fixed and postfixed with methanol but only partially reduced with ethanol. The staining with $14 \mathrm{~F} 7 \mathrm{Mab}$ was evidenced in the $89.2 \%$, $89.4 \%$, and $88.9 \%$ of lymphomas, lymph node metastasis, and other metastatic sites, respectively, but not in normal tissues. The treatment with 14F7 Mab affected both morphology and membrane integrity of P3X63Ag.653 cells. This cytotoxic activity was dose-dependent and ranged from 24.0 to $84.7 \%(10-1000 \mu \mathrm{g} / \mathrm{mL})$ as compared to the negative control. Our data could support the possible use of NeuGcGM3 as target for both active and passive immunotherapy against malignancies expressing this molecule.
\end{abstract}

\section{Introduction}

Lymphomas (primary malignant neoplasms of lymphoreticular origin) represent one of the major health problems worldwide [1]. Despite the availability of several options to the treatment of lymphomas [2], the identification of novel tumor-associated antigens that are universally expressed in these malignancies is necessary for the development of newer immunotherapeutic strategies [3].

On the other hand, as it is well known, the main cause of cancer-related death is due to metastasis of primary tumors to secondary sites within the body [4]. Usually, different 
primary tumors tend to spread to preferred metastatic sites, although both regional and distant lymph nodes are the most common metastatic targets for a variety of primary malignancies such as skin, breast, colon, stomach, and lung [5].

Gangliosides are sialic acid-containing glycosphingolipids engaged in many biological events that take place at vertebrate's cell membrane [6]. Unusual glycolylated gangliosides have been identified by immunohistochemical methods in some malignant tumors and their metastasis becoming attractive targets for immunotherapy [7-10].

The tissue reactivity of 14F7 Mab, a highly specific IgG1 against the NeuGcGM3 ganglioside, in a variety of frozen and formalin-fixed and paraffin-embedded malignant tumors have been previously published $[8,10-18]$. Nevertheless, up to now, there is no evidence about the staining of $14 \mathrm{~F} 7$ $\mathrm{Mab}$ in malignant lymphoma and nonmelanoma lymph node metastasis.

For these reasons, here we evaluated the reactivity of the 14F7 Mab in normal as well as in primary lymphoid tumors, lymph node, and other metastasis. Additionally, we assessed the effect of fixation in the recognition of 14F7 Mab as well as the ability of this Mab to bind NeuGcGM3 ganglioside inducing complement-independent cytotoxicity in a mouse myeloma cell line (P3X63Ag.653).

\section{Materials and Methods}

2.1. Cell Line and Monolayer Preparation. The mouse myeloma cell line P3X63Ag.653 (ATCC CRL-1580) was used. Cells were grown in Dulbecco's modified Eagle's media (PAA, E15-843) supplemented with 10\% heat-inactivated fetal bovine serum (PAA, A15-211), respectively. Cells were maintained at $37^{\circ} \mathrm{C}$ in a humidified atmosphere of air containing $5 \% \mathrm{CO}_{2}$ and the media was replaced every 3 to 4 days. Afterward, cultured cells were extensively washed with PBS (PAA, H15-002) and both cell viability and concentration were calculated by trypan blue exclusion assay followed by examination with a hemacytometer under an optical microscope. Only cells suspensions with viability greater than $90 \%$ were used. Then, cells were adjusted at 0.5 $\times 10^{6}$ cell $/ \mathrm{mL}$, deposed in histological slides, and air dried. Finally, slides were stored at $-20^{\circ} \mathrm{C}$ until they were used.

2.2. Monoclonal Antibodies. We used the 14F7 Mab (IgG1), a highly specific anti-NeuGcGM3 ganglioside antibody. This $\mathrm{Mab}$ was generated by immunization of Balb/c mice with NeuGcGM3 hydrophobically conjugated with human very low-density lipoproteins (VLDL) adjuvated with Complete Freud adjuvant (CFA). Afterwards, 14F7 Mab was obtained by the hybridoma resulting of the fusion of spleen cells with mouse myeloma cell line P3X63Ag.653 as described [8]. Additionally, the P3 Mab (IgM, k, anti-NeuGc-containing gangliosides and sulfated glycolipids) [7] (complementindependent cytotoxicity assays) or the 1E10 Mab (an antiidiotypic antibody specific for P3 Mab) [19] (immunocytochemistry assays) were used as negative controls.

2.3. Fixation Protocols and Immunocytochemical Procedure. Monolayers of P3X63Ag.653 cell line were fixed according to the following fixation protocols: $4 \%$ neutral buffered formaldehyde (Spectrum, F0110) and 4\% paraformaldehyde (BDH, 294474L) for 30 and 20 minutes at room temperature, respectively, and acetone (Spectrum, A1020), ethanol (Spectrum, E1028), and methanol (Spectrum, M1240) for 10 minutes at $2-8^{\circ} \mathrm{C}$ each one. Unfixed cells were also included. Additionally, samples were prefixed with $4 \%$ neutral buffered formaldehyde before fixation with acetone, ethanol, and methanol fixatives.

Afterwards, cells were rinsed and rehydrated in tris saline buffer, $\mathrm{pH} 7.6$ (TBS) for 10 minutes at room temperature. Then, samples were incubated for $1 \mathrm{~h}$ with $14 \mathrm{~F} 7$ or $1 \mathrm{E} 10$ (irrelevant) antibodies. After two rinses, a labelled polymerHRP (Dako, K1494) was added and the slides were incubated for 30 minutes. Finally, the enzymatic activity was visualized with AEC (Dako, K3461) and cells were contrasted with methyl green (Dako, S1962).

2.4. Tissue Specimens. Routinely processed, formalin-fixed, and paraffin-embedded archival samples with diagnosis of normal tissue (7), human lymphoma (37), lymph node metastasis of breast carcinoma (14), cutaneous malignant melanoma (17), colonic (12) and gastric (2) adenocarcinomas, lung cancer (1), and unknown primary tumor (1) as well as, other metastasis (9) were received from the pathology departments of both the National Institute of Oncology and Radiobiology and Manuel Fajardo General Hospital. All samples were used after the approved consent by the institutional ethical committees.

\subsection{Previous Processing and Immunohistochemical Staining.} Five microns serial sections from each block were obtained in a Lizt 1512 micrometer and mounted on plus slides (Dako, S2024). All sections were attached to the slide by heating in a $60^{\circ} \mathrm{C}$ oven for 1 hour. Afterwards, the slides were kept at room temperature and they were used within 30 days.

The slides were dewaxed in xylene and rehydrated in decreasing ethanol series as usually and endogenous peroxidase activity was blocked with dual endogenous enzyme block solution (Dako, S2003) for 10 minutes. Afterwards, all sections were washed in distilled water for 10 minutes and then were rinsed with TBS (Tris/saline buffer solution) for 5 minutes. The samples were incubated with the 14F7 Mabs for 1 hour at room temperature. Negative controls were performed by substituting primary antibody for TBS and sections of colonic adenocarcinoma of known positivity for NeuGcGM3 ganglioside were taken as positive control. After two rinses in TBS, the slides were incubated with a biotinylated link universal and streptavidin-HRP (Dako, K0690) for 30 minutes in each step. Between incubations, slides were washed with TBS for 10 minutes.

Afterwards, the enzymatic activity was visualized with a DAB (Dako, K3465) solution. For lymph node metastasis of malignant melanomas, AEC (Dako, K3461) was used. Finally, all slides were counterstained with Mayer's Hematoxylin (Dako, S2020), dehydrated, and mounted.

2.6. Immunostaining Evaluation. Staining of both cell membrane and cytoplasm was considered as positive for 14F7 Mab. 
TABLE 1: Effect of different fixatives in the 14F7 Mab reactivity.

\begin{tabular}{lcccccc}
\hline Intensity of & Unfixed & NBF & PFA & Acetone & Ethanol & Methanol \\
reaction & +++ & +++ & +++ & ++ & ++ & - \\
\hline
\end{tabular}

Legend: NBF: neutral buffered formalin; PFA: paraformaldehyde. Intensity: - negative, ++ moderate, +++ intense.

TABLE 2: Effect of postfixation in the 14F7 Mab recognition.

\begin{tabular}{lcccc}
\hline Intensity of & NBF & NBF/acetone & NBF/ethanol & $\mathrm{NBF} /$ methanol \\
reaction & +++ & +++ & ++ & -
\end{tabular}

Legend: NBF: neutral buffered formalin. Intensity: - negative, ++ moderate, +++ intense.

For immunocytochemical assays, the intensity of reaction of each sample was judged as negative $(-)$, weak $(+)$, moderate $(++)$, and strong $(+++)$. For immunohistochemical determinations, a semiquantitative scoring system was used to define levels of reactivity. The recognition of 14F7 Mab was evaluated for percentage of positive cells $(0-100 \%)$ and the intensity of reaction $(0-3+)$. The score was calculated for each specimen by multiplication of the intensity of reaction and the grade of positive cells, resulting in a score ranging from 0 to 300 . Subsequently, these scores were grouped as follows: 0 (score 0); 1 (scores 1-100); 2 (scores 101-200), and 3 (scores 201-300).

2.7. Complement-Independent Cytotoxicity. The induction of cell death procedures as previously described [20] with minor modifications was used. Briefly, P3X63Ag.653 cells were resuspended in culture medium with $1 \%$ bovine serum albumin (BSA) (Sigma, A2153) at $0.25 \times 10^{6}$ cells $/ \mathrm{mL}$ and incubated with $14 \mathrm{~F} 7 \mathrm{Mab}(10-1000 \mu \mathrm{g} / \mathrm{mL})$ in a $5 \% \mathrm{CO}_{2}$ atmosphere at $37^{\circ} \mathrm{C}$ for 2 hours. Cells were washed, resuspended in FACSFlow (Becton-Dickinson, 342003) and maintained in ice bath. Afterwards, cells were resuspended with FACSFlow and stained with propidium iodide (PI) at a final concentration of $4 \mu \mathrm{g} / \mathrm{mL}$. The percentage of PIpositive cells was measured using a FACScan flow cytometer (Becton-Dickinson). Cells that were stained red with PI were considered as dead.

\section{Results}

3.1. The Recognition of $14 F 7$ Mab Varies Depending on the Protocol Fixation. The effect of a variety of fixation protocols on the 14F7 Mab immunoreaction was evaluated in monolayers of P3X63Ag.653 cell line (see Section 3). A homogeneous and finely granular reactivity of 14F7 Mab was evidenced in unfixed as well as in $4 \%$ neutral-buffered formaldehyde and $4 \%$ paraformaldehyde fixed cells (Table 1, Figure 1(a)). In acetone fixed cells, both a slight diminishing in the intensity of reaction with 14F7 Mab and the appearance of cells with a grosser granular staining mainly located in the cytoplasm were observed (Figure 1(b)). On the other hand, the staining with 14F7 Mab was only partially reduced after fixation (Figure 1(c)) and postfixation with ethanol while, postfixation with acetone did not alter the localization of the ganglioside (Table 2 ). The reactivity with $14 \mathrm{~F} 7 \mathrm{Mab}$ was significantly eliminated in both cells fixed and postfixed with methanol (Figures 1(d) and 1(e)). No immunoreaction, independently of the fixation protocol, was detected in cells incubated with 1 E10 Mab which was used as negative control (Figure 1(f)).

3.2. No Staining with 14F7 Mab Was Evidenced in Normal Tissues. No reactivity of $14 \mathrm{~F} 7 \mathrm{Mab}$ was evidenced in normal tonsil (0/2), lymph node (0/2), and spleen $(0 / 3)$.

\subsection{Higher Levels of $14 F 7$ Mab Reactivity Were Detected in} Sections of Primary Lymphoid Tumors. The 14F7 Mab reactivity was detected in 33/37 (89.2\%) of all studied lymphomas not depending on the histopathological subtype (Table 3 ). In $21 / 33(63.6 \%)$ cases, a moderate to intense reaction with 14F7 Mab in more than $40 \%$ of malignant lymphocytes was observed, while $12 / 33$ (36.4\%) sections displayed a weak staining with this Mab. In general, the recognition of 14F7 Mab was observed as a finely granular reaction mainly located in the cell membrane but also in the cytoplasm of malignant cells (Figure 2). No immunostaining was evidenced in negative controls.

3.4. The 14F7 Mab Immunostaining Was Observed in Lymph Node Metastasis. An intense reactivity of $14 \mathrm{~F} 7 \mathrm{Mab}$ was detected in almost all tumor cells in 11/12 (91.7\%) and $2 / 2$ of lymph node metastasis of breast ductal and lobular carcinomas, respectively (Table 4). The recognition of 14F7 Mab was homogeneous and finely granular and was mainly located in the membrane of malignant cells although the cytoplasm was also decorated (Figure 3). Only one case of breast ductal carcinoma (8.3\%) exhibited a weak to moderate and diffuse pattern of staining.

Concerning lymph node metastases of cutaneous melanoma, the reactivity of $14 \mathrm{~F} 7 \mathrm{Mab}$ was detected in more than $50 \%$ of malignant cells in $15 / 17$ (88.2\%) (Table 4$)$. The recognition of the $14 \mathrm{~F} 7 \mathrm{Mab}$ was variable in the intensity of reaction (from weak to intense). A weak to moderate staining with 14F7 Mab was observed in 3/15 (20.0\%) of samples while in $12 / 15(80.0 \%)$ of them, a moderate to intense staining was evidenced. Only one case showed a moderate reaction with 14F7 Mab in less than 25\% of malignant cells.

Lymph node metastasis of colonic adenocarcinomas exhibited a homogeneous and finely granular reaction with 14F7 Mab in 9/12 (75.0\%) cases, not taking into account the grade of differentiation (Table 4 ). The intensity of this reaction varied from moderate to intense and was observed in the cell membrane and also in the cytoplasm of more than $70 \%$ of malignant glandular cells (Figure 4). Similar results were evidenced in lymph node metastasis of gastric adenocarcinoma (2/2), lung adenocarcinoma (1/1) (Figure 4), and carcinoma of unknown primary origin (1/1).

Additionally, in 3/14 (21.4\%) of lymph node metastasis of breast carcinoma as well as in $2 / 9(22.2 \%)$ of colon adenocarcinomas, a weak to intense reaction of 14F7 Mab was observed in lymphocytes of tumor adjacent areas (Figures 3(a), 3(b), 4(a), and 4(b)).

3.5. Other Metastatic Sites Were Also Reactive with 14F7 Mab. A moderate to intense immunoreaction with 14F7 Mab was 
TABLE 3: Immunostaining of 14F7 Mab in primary lymphoid tumors.

\begin{tabular}{|c|c|c|c|c|c|}
\hline \multirow{2}{*}{ Lymphoid tumors } & \multicolumn{5}{|c|}{ Score } \\
\hline & 0 & 1 & 2 & 3 & Total (\%) \\
\hline \multicolumn{6}{|l|}{ Mature B-cell neoplasms } \\
\hline Small lymphocytic lymphoma & 0 & 2 & 1 & 1 & $4 / 4$ \\
\hline Plasma cell myeloma & 0 & 0 & 1 & 1 & $2 / 2$ \\
\hline Follicular lymphoma & 0 & 3 & 1 & 0 & $4 / 4$ \\
\hline Diffuse large B-cell lymphoma & 2 & 4 & 6 & 6 & $16 / 18(88.9)$ \\
\hline Burkitt lymphoma & 0 & 1 & 0 & 0 & $1 / 1$ \\
\hline Classical Hodgkin lymphoma & 1 & 1 & 1 & 0 & $2 / 3(66.7)$ \\
\hline Unclassified & 1 & 0 & 1 & 3 & $4 / 5(80.0)$ \\
\hline
\end{tabular}

Legend: 0 (score 0); 1 (scores 1-100); 2 (scores 101-200), and 3 (scores 201-300).

TABLE 4: Immunorecognition of 14F7 Mab in some lymph node metastasis.

\begin{tabular}{|c|c|c|c|c|c|}
\hline \multirow{2}{*}{ Lymph node metastasis of } & \multicolumn{5}{|c|}{ Score } \\
\hline & 0 & 1 & 2 & 3 & Total $(\%)$ \\
\hline Cutaneous melanoma & 2 & 2 & 8 & 5 & $15 / 17(88.2)$ \\
\hline \multicolumn{6}{|l|}{ Breast carcinoma } \\
\hline Ductal & 0 & 0 & 0 & 12 & $12 / 12$ \\
\hline Lobular & 0 & 0 & 0 & 2 & $2 / 2$ \\
\hline Peritumoral lymphocytes & 11 & 1 & 1 & 1 & $3 / 14(21.4)$ \\
\hline Colonic adenocarcinoma & 3 & 0 & 3 & 6 & $9 / 12(75.0)$ \\
\hline Peritumoral lymphocytes & 7 & 1 & 1 & 0 & $2 / 9(22.2)$ \\
\hline Gastric adenocarcinoma & 0 & 0 & 1 & 1 & $2 / 2$ \\
\hline Lung carcinoma & 0 & 0 & 0 & 1 & $1 / 1$ \\
\hline Unknown primary origin & 0 & 0 & 1 & 0 & $1 / 1$ \\
\hline
\end{tabular}

Legend: 0 (score 0); 1 (scores 1-100); 2 (scores 101-200), and 3 (scores 201-300).

obtained in both cutaneous (1/1) and subcutaneous (3/3) metastasis of primary malignant melanoma. The staining was homogeneous and was mainly located on the plasmatic membrane of more than $90 \%$ of malignant cells although the cytoplasm was also reactive. Other metastatic tumors such as neuroblastoma (1/1), renal cell carcinoma (1/1), and those from unknown origin $(2 / 2)$ were also recognized by 14F7 Mab. No reactivity was evidenced in a metastatic thymic carcinoma (Table 5).

3.6. Treatment with 14F7 Mab Induces a Complement-Independent Cytotoxicity in a Dose-Dependent Manner. The ability of 14F7 Mab to induce a complement-independent cytotoxicity after binding to NeuGcGM3-positive cell line (P3X63Ag.653) was evaluated. This effect was tested by PI internalization and flow cytometry analysis. The treatment with 14F7 Mab affected both morphology and membrane integrity of tumor cells. After treating P3X63Ag.653 cells with 14F7 Mab, a subpopulation exhibiting both cell size (FSC$\mathrm{H}$ ) and internal complexity (SSC-H) alterations (Figures 5(a) and 5(b)), as well as a positive staining with PI were observed (Figures 5(c) and 5(d)). The cytotoxic activity of 14F7 Mab was dose-dependent and ranged from 24.0 to $84.7 \%$ as compared to the negative control, obtaining the maximum of cell death at $1000 \mu \mathrm{g} / \mathrm{mL}$. This effect was not seen when cells were treated with P3 Mab used as negative control.

\section{Discussion}

The use of frozen samples is desirable for any determination of gangliosides, but it is known, this kind of samples is often difficult to obtain and, even when available, to conserve. For these reasons, the most common specimen available for immunohistochemical assays after the histopathological diagnosis is formalin-fixed, ethanol and xylene-processed, and paraffin-embedded tissues. But, gangliosides are usually damaged or extracted after the routine treatment of tissues with organic solvents, due to their glycosphingolipid chemical structure.

In this paper, we demonstrated that cells fixation plays an important role for the immunolocalization of NeuGcGM3 by mean of 14F7 Mab. As expected, both fixation and postfixation with methanol completely removed NeuGcGM3 ganglioside from P3X63Ag.653 cells, consistent with the solubility of the glycolipid antigens [21]. While fixation with acetone only lead to slight decreasing in the intensity of reaction with 14F7 Mab joint to little alterations in the localization of NeuGcGM3. These results seem to be related to a complete 
TABLE 5: Immunoreactivity of 14F7 Mab in other metastasis.

\begin{tabular}{|c|c|c|c|c|c|}
\hline \multirow{2}{*}{ Metastasis of } & \multicolumn{5}{|c|}{ Score } \\
\hline & 0 & 1 & 2 & 3 & Total (\%) \\
\hline \multicolumn{6}{|l|}{ Cutaneous melanoma } \\
\hline Subcutaneous & 0 & 0 & 1 & 2 & $3 / 3$ \\
\hline Cutaneous & 0 & 0 & 0 & 1 & $1 / 1$ \\
\hline Thymic carcinoma & 1 & 0 & 0 & 0 & $0 / 1$ \\
\hline Neuroblastoma & 0 & 0 & 0 & 1 & $1 / 1$ \\
\hline Renal cell carcinoma & 0 & 0 & 0 & 1 & $1 / 1$ \\
\hline Unknown primary origin & 0 & 1 & 0 & 1 & $2 / 2$ \\
\hline
\end{tabular}

Legend: 0 (score 0); 1 (scores 1-100); 2 (scores 101-200), and 3 (scores 201-300).

partial extraction and/or displacing of this ganglioside from cells, similar to previous studies [21]. Consequently, methanol and acetone should be excluded as fixatives in the detection of NeuGcGM3 because both solubilize this ganglioside to different extents.

On the other hand, paraformaldehyde is one of the most common and adequate fixatives used in the immunolocalization of gangliosides $[7,8]$. It is known that paraformaldehyde is a polymerization product of formaldehyde and to prevent its formation, formalin solutions usually contain different percentages of methanol (10-15\%). Here, we obtained an intense reactivity of $14 \mathrm{~F} 7 \mathrm{Mab}$, mainly located in the membrane of P3X63Ag.653 cells after both 4\% paraformaldehyde and $4 \%$ neutral-buffered formalin (NBF) fixations. These results permit to consider that the low percentage of methanol present in the final solution of NBF is not able to be removed NeuGcGM3 from cells. In this way, our data also could support the use of NBF fixation in the immunodetection of NeuGcGM3 ganglioside.

In addition, some authors have suggested that the routine tissues processing do not extract or damage the antigenic carbohydrate determinants of gangliosides [22]. Curiously, fixation and postfixation with ethanol only induce a partial extraction and/or damage of NeuGcGM3 ganglioside from the P3X63Ag.653 myeloma cells. These results are suggestive that carbohydrate determinant recognized by 14F7 probably resists the formalin fixation and the ethanol tissues processing, permitting its detection in this kind of samples. In line with this, the expression of NeuGcGM3 and NeuGcGDla gangliosides in formalin-fixed and paraffin-embedded tissues using GMR8 Mab by immunohistochemical and TLC immunostaining methods has been recently demonstrated [23].

Aberrant and elevated expression of some gangliosides has been previously demonstrated on the surface of lymphoid derived tumors $[24,25]$. In previous studies, GM3 was the predominant ganglioside found in pre-B lymphoma cells and B-cell neoplasms using over-pressured thin-layer chromatography (OPTLC) followed by scanning densitometry and high performance thin layer chromatography (HPTLC) and immune thin layer chromatography (ITLC), respectively. Nevertheless, these studies have been restricted to gangliosides containing the $\mathrm{N}$-acetylated variant of sialic acid (NeuAc) $[24,25]$.
In the present work, we reported for the first time the tissue reactivity of the $14 \mathrm{~F} 7 \mathrm{Mab}$, a highly specific IgG1 against the N-glycolylated variant of GM3 ganglioside, in a variety of lymphoid tumors not related with the histopathological typing, but not in normal tissues. The pattern of staining of 14F7 was finely granular, homogeneous, and mainly located in cell membrane of malignant lymphocytes, similar to that observed in preceding reports in other tumor localizations [10, 14-17].

The expression of the $\mathrm{N}$-glycolylated variant of sialic acid (NeuGc) forming the structure of gangliosides and/or other glycoconjugates (Hangnutziu-Deicher antigen, HD) in humans has been considered as a tumor-associated antigen [26]. Normal cells are capable to synthetize the sialic acid $\mathrm{N}$-acetylneuraminic acid but not $\mathrm{N}$-glycolylneuraminic acid (as a result of a deletion in the cytidine monophospho$\mathrm{N}$-acetylneuraminic acid hydroxylase gene). The aberrant expression of NeuGc residues in humans has been related to the metabolic incorporation from red meat and dairy products in the diet due to the altered metabolism of malignant cells [27-29]. However, some authors have reported an alternative pathway to the NeuGc synthesis from other intermediates of cellular metabolism in some human tumors [27]. The expression of NeuGc also triggers the immune responses to the nonhuman sialic acid, which is the mechanism of the "serum sickness" reaction previously described as HD antibodies [30,31]. These HD antibodies were found to react with NeuGc bound to horse serum glycoconjugates and were then discovered in the serum and tissues of patients with cancer [30] and in activated and malignant immune cells [32].

The expression of heterophile HD antigen on the cell surface of both leukemia and malignant lymphoma was evidenced by membrane immunofluorescence staining with chicken antiserum against NeuGcGM3 and fluoresceinconjugated rabbit anti-chicken IgG [26]. The aberrant expression of NeuGc forming part of human lymphoma glycosphingolipids using gas chromatography-mass spectrometry had been also demonstrated [33]. Moreover, the expression of HD antigen in both pathologic sera and extracts of cancer tissues from lymphoma and leukemia had been previously detected by means of inhibition of agglutination of bovine erythrocytes by HD antibodies [30]. However, in other studies, no serum antibodies against HD antigen were detected in patients bearing lymphomas [34]. 


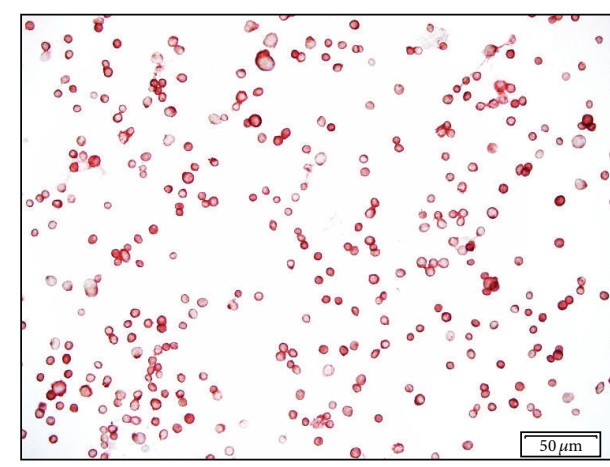

(a)

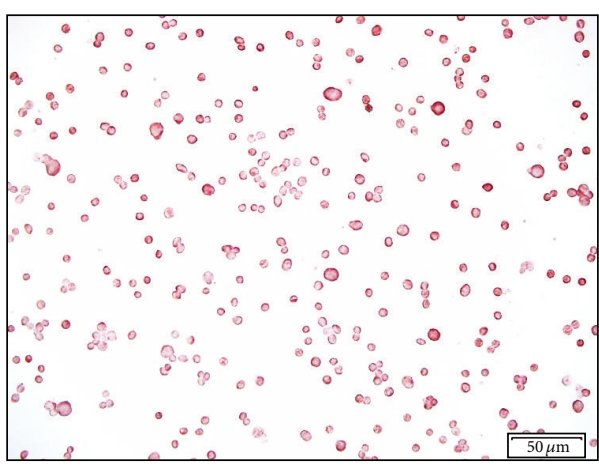

(c)

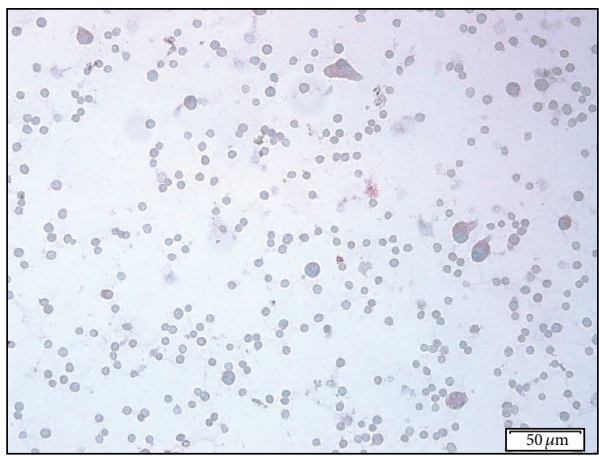

(e)

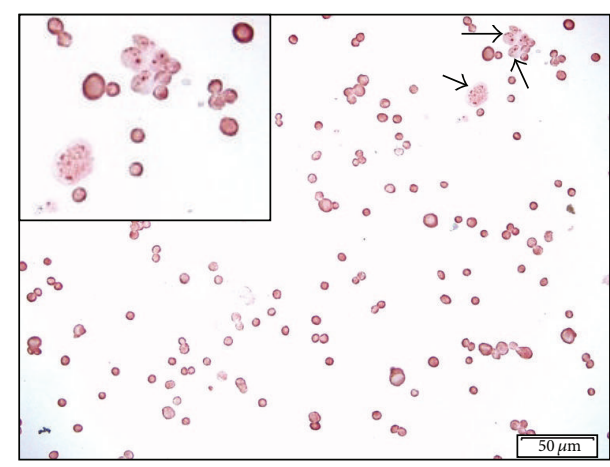

(b)

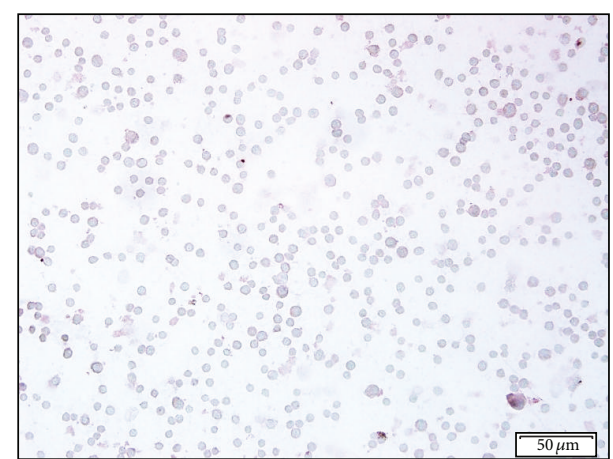

(d)

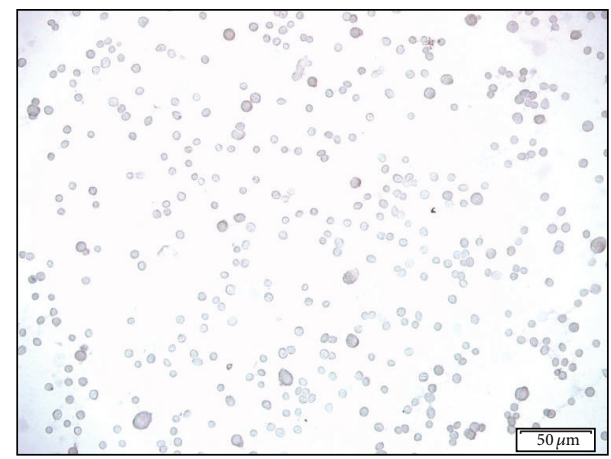

(f)

Figure 1: Microphotographs of the 14F7 Mab reactivity in P3X63Ag.653 cell line after different fixation protocols. An intense, homogeneous, and finely granular reactivity of 14F7 Mab was observed in cells fixed with $4 \%$ neutral-buffered formaldehyde (a). Observe: both the slight diminishing in the intensity of reaction and the appearance of cells with a grosser granular staining mainly located in the cytoplasm after fixation with acetone (b) (black arrows). Inset on the upper-left corner, 400x magnification. The 14F7 Mab staining was only partially diminished after fixation with ethanol (c) while, the reactivity with this Mab was significantly removed in cells fixed and postfixed with methanol ( $\mathrm{d}$ and e, resp.). No immunoreaction was detected in cells incubated with $1 \mathrm{E} 10 \mathrm{Mab}$ (negative control) $(\mathrm{d})$. White bar $=50 \mu \mathrm{m}$.

Additionally, we found the recognition of 14F7 Mab in most of lymph node metastasis of some primary tumors such as colonic and gastric adenocarcinoma, cutaneous malignant melanoma, breast tumors, and lung carcinoma. A preliminary study of the 14F7 Mab staining in cutaneous and subcutaneous metastasis of melanoma and other metastasis was also showed. Similar pattern of immunostaining and percentages of positive cells were obtained by our group in the corresponding primary malignancies $[10,14-16]$. In previous reports, the 14F7 Mab was able to intensely stain cells of metastatic lymph nodes of cutaneous malignant melanoma $[9,14]$. Moreover, another Mab (P3), reported by our group, binds to several NeuGc containing gangliosides and also reacts with sulfated glycolipids showed a positive staining in lymph node metastasis of breast tumors [7]. Interestingly, specific therapies anti-NeuGcGM3 ganglioside using molecular cancer vaccines have shown promising results in patients bearing lymph node metastasis of breast tumors and cutaneous malignant melanoma [35-37]. In this way, although in some cases the number of metastasis samples 


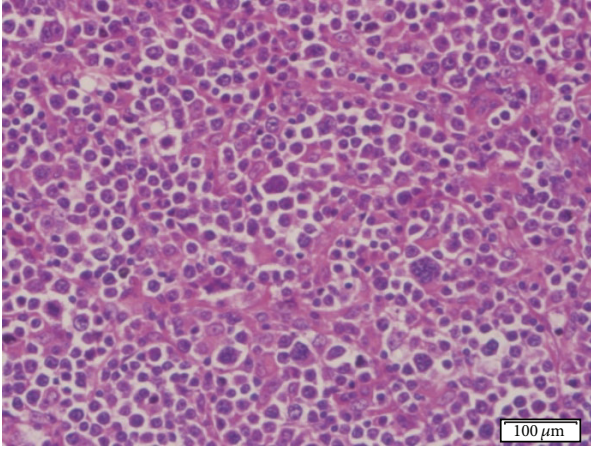

(a)

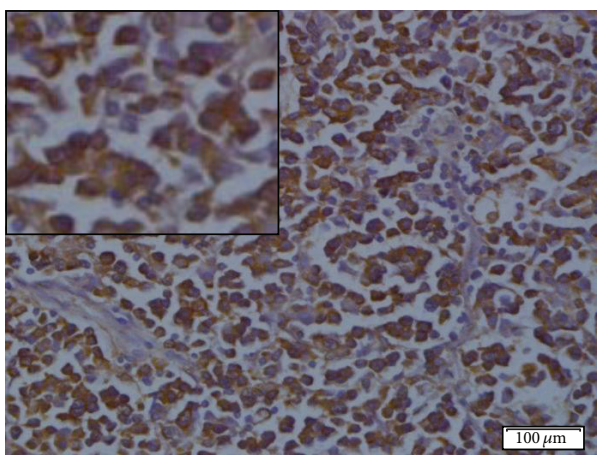

(c)

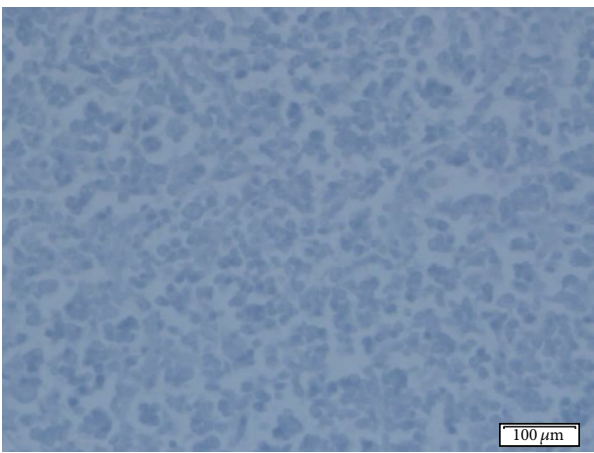

(e)

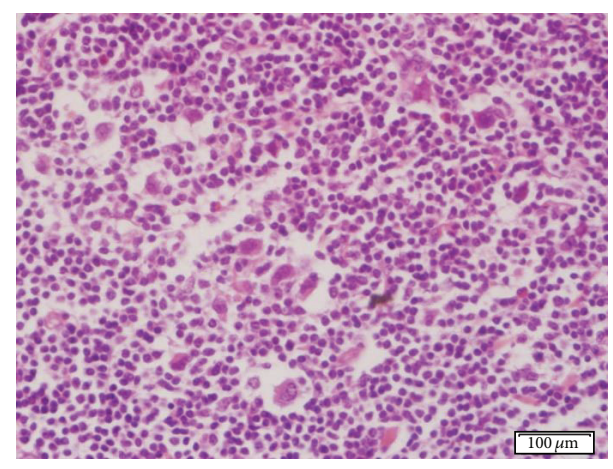

(b)

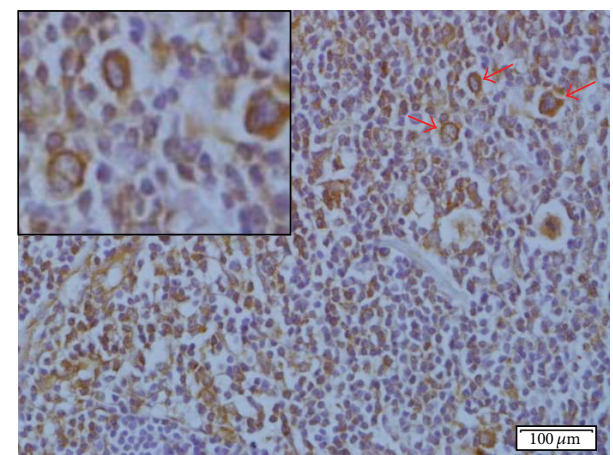

(d)

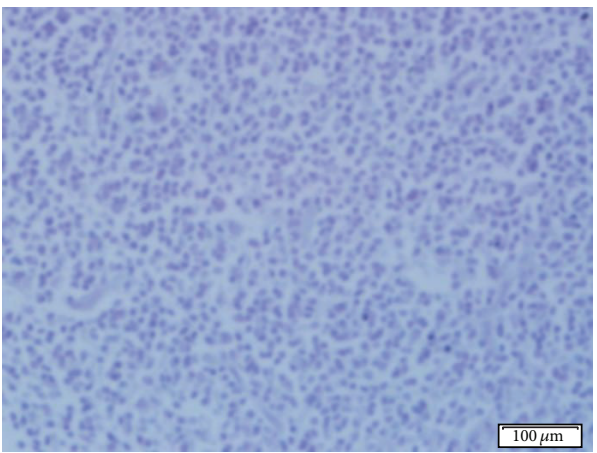

(f)

Figure 2: Microphotographs of the 14F7 Mab reactivity in human lymphoma. (a) and (b): Hematoxylin and eosin staining of diffuse large B-cell lymphoma and nodular sclerosis classical Hodgkin lymphoma, respectively. (c) and (d): Immunostaining with 14F7 Mab. Note: the intense reactivity of 14F7 Mab in both the cell membrane and cytoplasm of both malignant B lymphocytes (c) and Hodgkin cells (d) (red arrows). Inset on the upper-left corner, 400x magnification. (e) and (f): Negative controls. Observe: the absence of staining. White bar = $100 \mu \mathrm{m}$.

is small, it would be interesting to extent the evaluation of NeuGcGM3 expression in these malignancies in order to assess its potential use as target for immunotherapy.

On the other hand, gangliosides can be actively shed from the cell surface of malignant cells and taken up by other cells by insertion of their lipid anchors into the membrane [38]. In addition, shedding of immunosuppressive gangliosides to the tumor microenvironment has been reported to be an important characteristic of human malignancies [39]. These circulating gangliosides are potentially involved in tumorhost interactions contributing to cancer progression [40] and metastasis through tumor immune escape [41].
Here, it was observed a reactivity of 14F7 Mab in the cell membrane of normal lymphocytes localized around both metastatic breast carcinoma cells of axillary lymph nodes and metastatic colon adenocarcinoma cells of local lymph nodes (Figures 3(b) and 4(b), red arrows). It is known that sentinel lymph nodes are the first nodes to receive lymphatic drainage from a primary tumor and the preferential site of initial tumor metastasis. These lymph nodes are intensively exposed to the bioactive products of tumor cells and other associated cells [42]. Increased tumor-derived NeuGcGM3 ganglioside in sentinel lymph nodes have been suggested to directly influence coordinated interactions between DC 


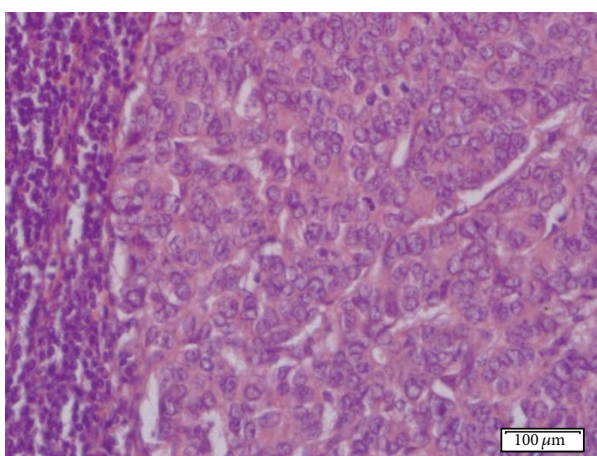

(a)

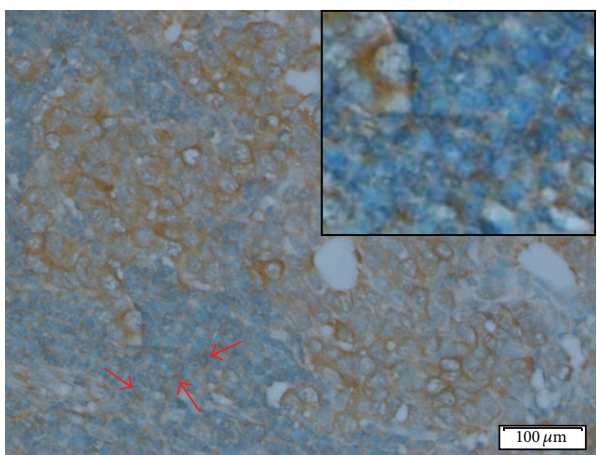

(c)

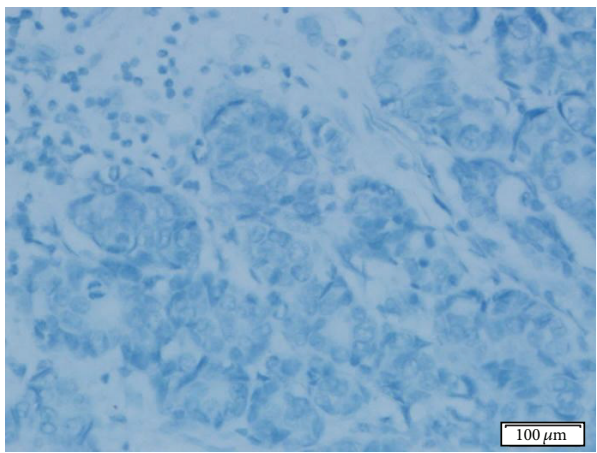

(e)

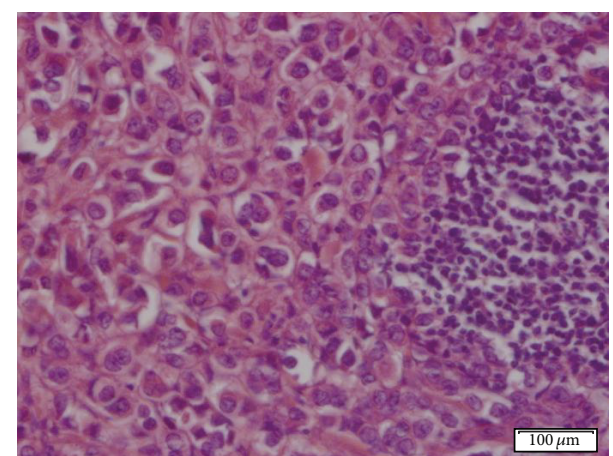

(b)

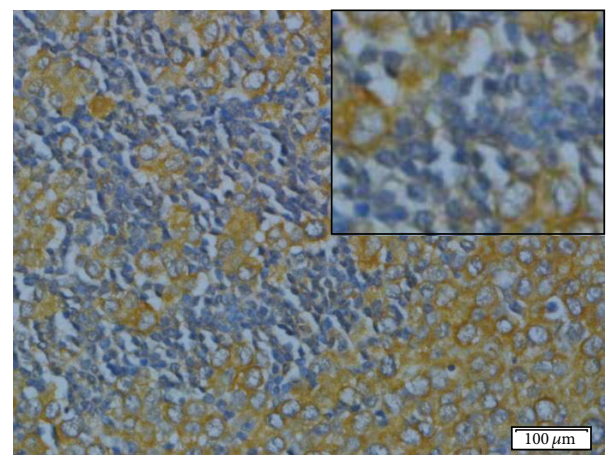

(d)

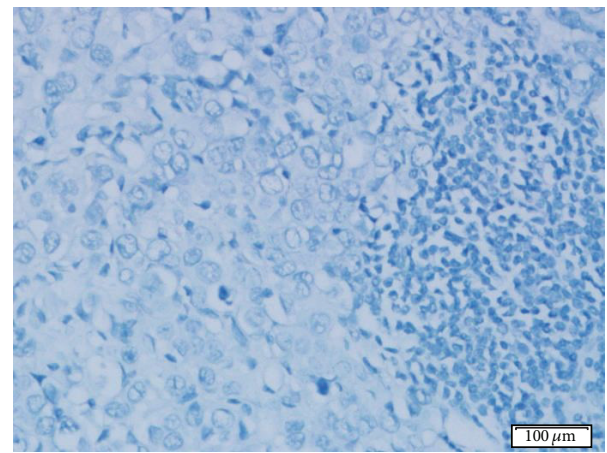

(f)

FIgURE 3: Microphotographs of the 14F7 Mab reaction in lymph node metastasis. (a) and (b): Hematoxylin and eosin staining of lymph node metastasis of breast ductal and lobular adenocarcinomas, respectively. (c) and (d): Immunostaining with 14F7 Mab. Observe: an intense reaction of 14F7 Mab located in both cell membrane and cytoplasm of malignant epithelial cells. See: an intense immunostaining in lymphocytes of tumor adjacent areas (c) (red arrows). Inset on the upper-right corner, 400x magnification. Note: the absence of reactivity in peritumoral lymphocytes (d). (e) and (f): Negative controls. Observe: the lack of staining. White bar $=100 \mu \mathrm{m}$.

and both helper and regulatory $\mathrm{CD}^{+} \mathrm{T}$ cells abrogating an anti-tumor-specific immune response [41]. In this way, our results seem to be in agreement with the potential shedding of NeuGcGM3 ganglioside by metastatic epithelial cells in secondary lymphoid organs as well as with its incorporation to the cell membrane of peritumoral lymphocytes.

Finally, we showed the ability of 14F7 murine Mab to directly kill the NeuGcGM3-positive murine myeloma cells without participation of complement. This Mab, after binding to NeuGcGM3, significantly induced the appearance of a subpopulation with increased cell size and internal complexity measured by flow cytometry. In addition, a decreasing in the tumor cell viability in a dose-dependent manner using the staining with PI was also observed in this subpopulation. Similar results had been previously reported [20,43]. Nevertheless, the selection of patients to any anti-NeuGcGM3 specific therapies has been usually based on the tissue reactivity of the 14F7 murine Mab, which is typically used only for diagnostic purposes. It is known that therapy with murine-derived Mabs is limited by their tendency to develop human anti-mouse antibodies response (HAMA), the relatively short half-life of the Mabs 


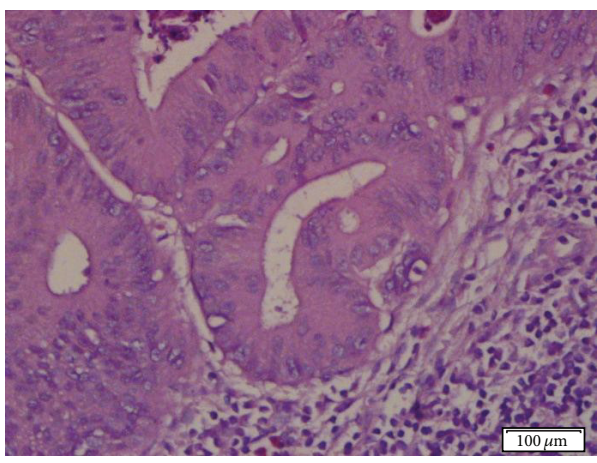

(a)

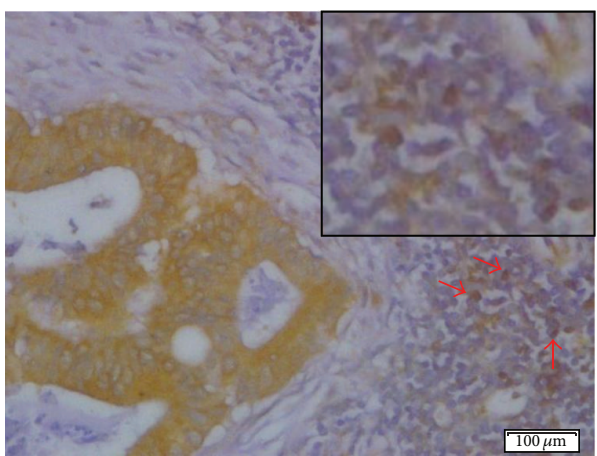

(c)

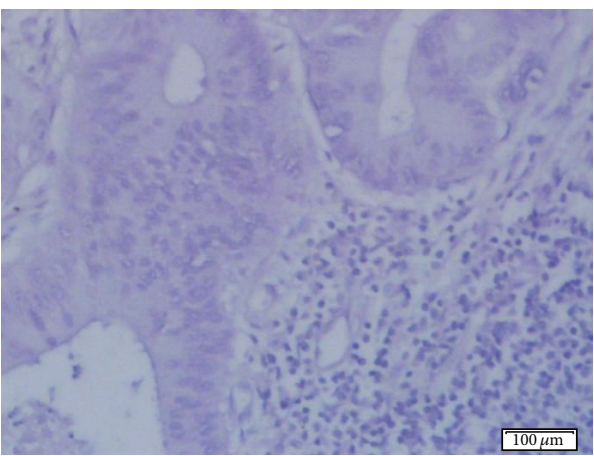

(e)

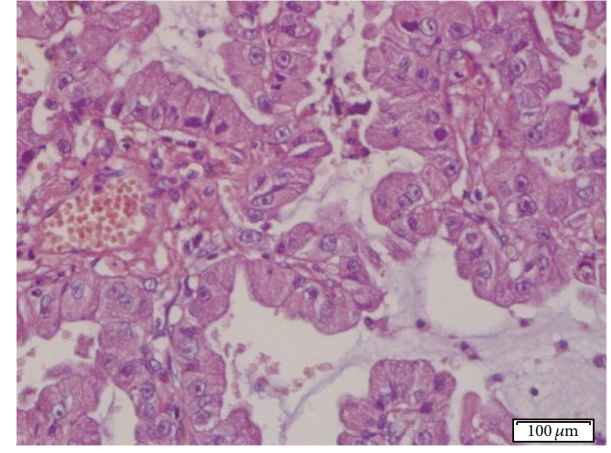

(b)

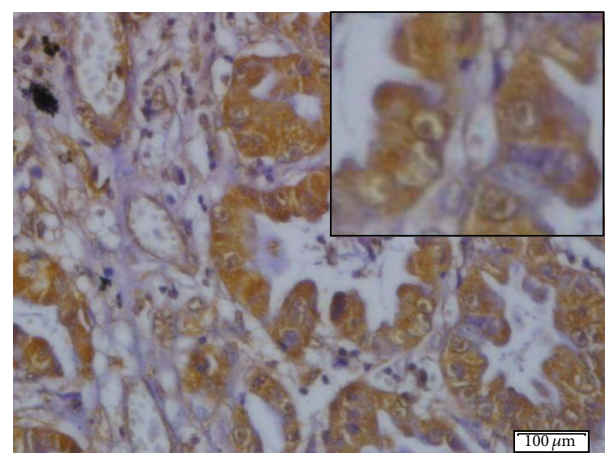

(d)

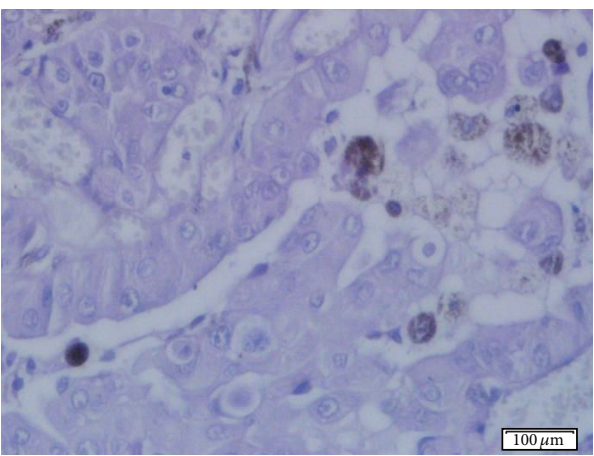

(f)

Figure 4: Microphotographs of the 14F7 Mab staining in lymph node metastasis. (a) and (b): Hematoxylin and eosin staining of lymph node metastasis of colonic and lung adenocarcinomas, respectively. (c) and (d): Immunoreactivity of the 14F7 Mab. Observe: an intense reaction of 14F7 Mab located in both cell membrane and cytoplasm of malignant epithelial cells. See: a moderate immunostaining in lymphocytes of tumor adjacent areas (red arrows). Inset on the upper-right corner, 400x magnification. (e) and (f): Negative controls. Observe: the lack of staining. White bar $=100 \mu \mathrm{m}$.

and the limited ability of murine Fc to activate human immune mechanisms [44]. For that reason, in the last few years, a chimeric and humanized variant of 14F7 Mab were developed in our center. The resulting recombinant Mabs exhibited a similar ability to bind NeuGcGM3 and to induce complement- independent cytotoxicity as compared with the murine counterpart $[20,45]$. In this sense, 14F7 Mab becomes a useful tool to identify tumors that could be sensitive to anti-NeuGcGM3 specific therapies, including passive immunotherapy using a chimeric and/or the humanized version of this Mab.

\section{Conclusions}

In summary, we reported the tissue reactivity of 14F7 Mab in both primary and secondary malignancies of lymphoid system. Evidence that probably support the potential resistance of the antigenic determinant recognized by $14 \mathrm{~F} 7$ to formalin fixation and tissues processing were also showed. In addition, the capacity of 14F7 Mab to induce complement-independent cytotoxicity in a myeloma-derived cell line after binding NeuGcGM3 was demonstrated. Our data could support the possible use of NeuGcGM3 as target for both active 


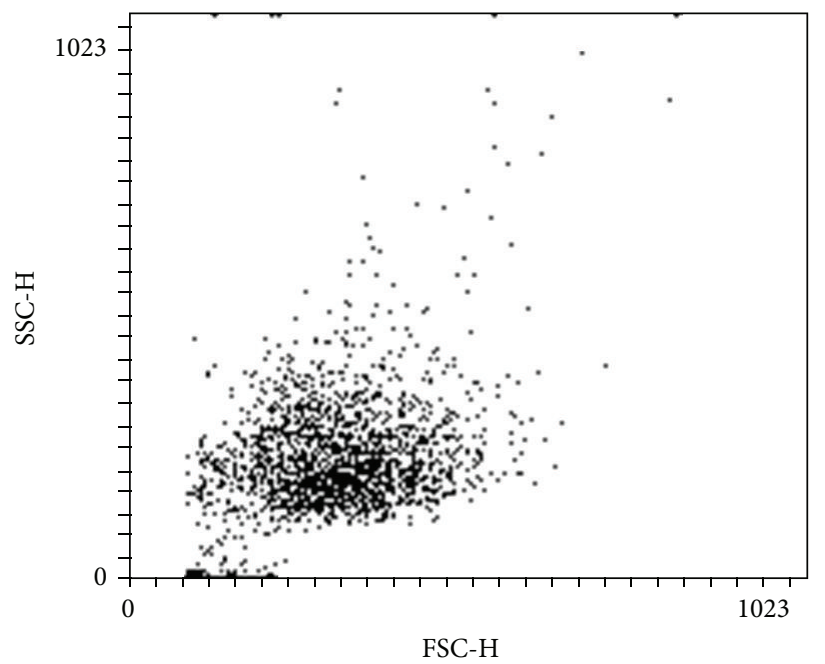

(a)

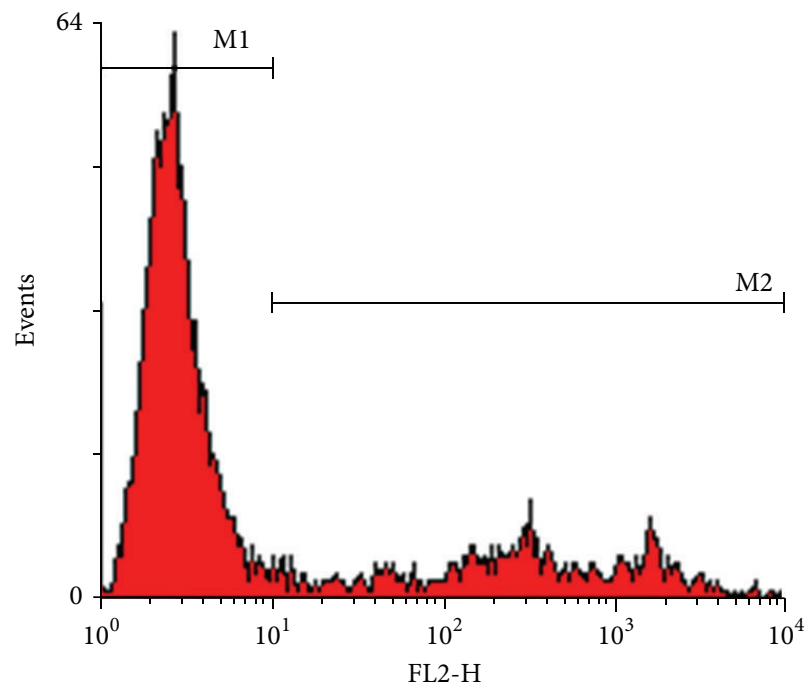

(c)

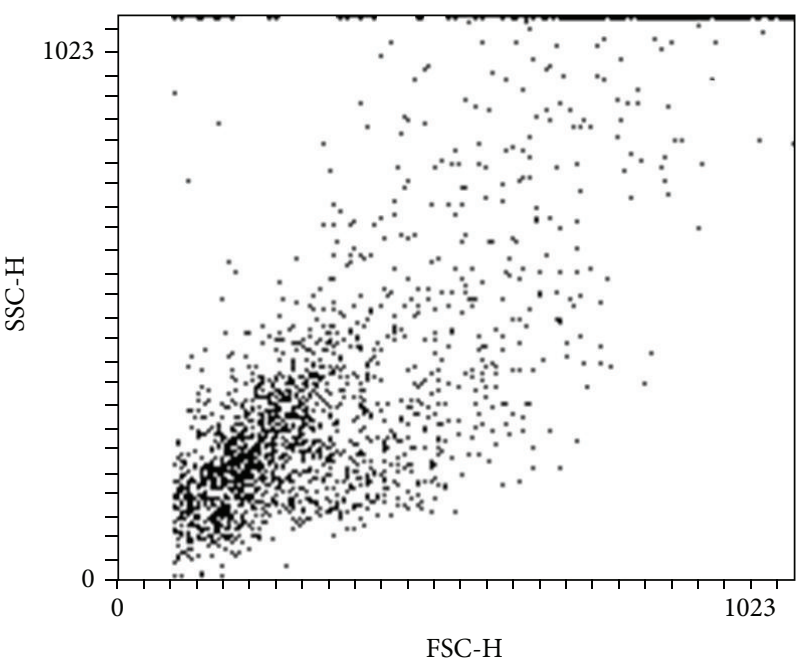

(b)

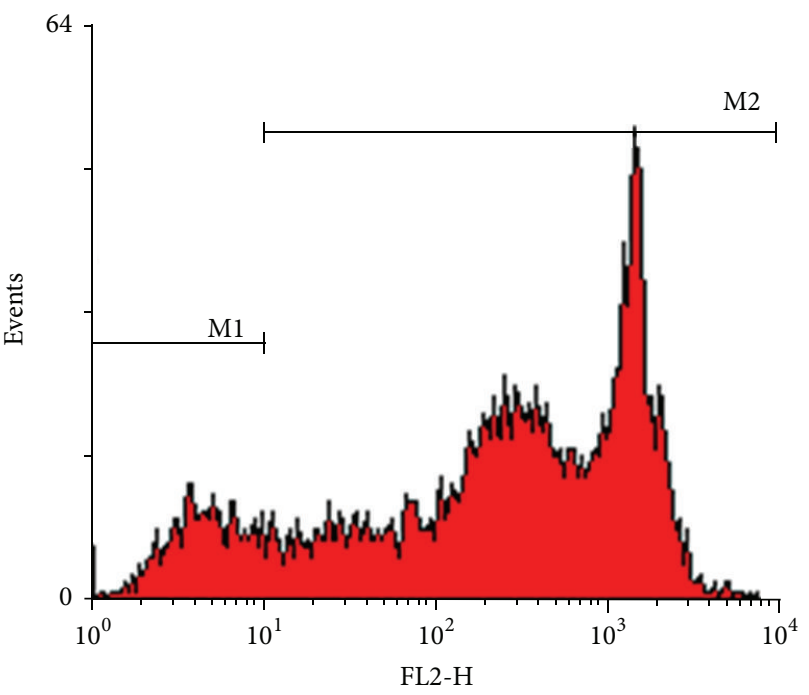

(d)

FIGURE 5: Representative flow cytometric profiles of complement-independent cytotoxicity of 14F7 Mab in the murine myeloma derived cell line, P3X63Ag.653. (a) and (b): Dot plots graphs. Correlated measurements of FSC-H (cell-surface area or size) and SSC-H (cell granularity or internal complexity) permit to detect changes in the light scattering properties of cells. Observe: a homogeneous population of cells treated with P3 Mab (irrelevant control) (a). The treatment with 14F7 Mab altered the morphology of P3X63Ag.653 cells, characterized by changes in cell size and granularity based on both FSC-H and SSC-H parameters analysis (b). (c) and (d): Histogram graphs showing the discrimination of viable (M1) and nonviable (M2) cells using the propidium iodide (PI) staining. These graphs correspond to (a) and (b), respectively. Nonviable cells uptake this dye fluorescing brightly in the red range of the visible color spectrum (FL2-H). A limited fraction of P3X63Ag.653 cells showed a positive staining with PI after incubation with P3 Mab (M2 region). Note: the dramatic decreasing in the cell viability after treatment with 14F7 Mab.

and passive immunotherapy of malignancies expressing this molecule. Moreover, our results permit to consider the use of 14F7 murine Mab to identify lymphoid tumors that could be sensitive to anti-NeuGcGM3 specific therapies. Experiments in order to evaluate the recognition of 14F7 Mab in human leukemia are ongoing by our group.

\section{Conflict of Interests}

The authors declare that there is no conflict of interests.

\section{Authors' Contribution}

Rancés Blanco and Damián Blanco equally contributed to this work.

\section{Acknowledgment}

Financial support was provided by the Center of Molecular Immunology. 


\section{References}

[1] A. M. El-Sayed, M. H. El-Borai, A. A. Bahnassy, and S. M. S. El-Gerzawi, "Flow cytometric immunophenotyping (FCI) of lymphoma: correlation with histopathology and immunohistochemistry," Diagnostic Pathology, vol. 3, no. 1, article 43, 2008.

[2] D. Berthold and M. Ghielmini, "Treatment of malignant lymphoma," Swiss Medical Weekly, vol. 134, no. 33-34, pp. 472-480, 2004.

[3] J. Weng, S. Rawal, F. Chu et al., "TCL1: a shared tumorassociated antigen for immunotherapy against B-cell lymphomas," Blood, vol. 120, no. 8, pp. 1613-1623, 2012.

[4] E. L. Walk and S. A. Weed, "Recently identified biomarkers that promote lymph node metastasis in head and neck squamous cell carcinoma," Cancers, vol. 3, no. 1, pp. 747-772, 2011.

[5] G. DiSibio and S. W. French, "Metastatic patterns of cancers: results from a large autopsy study," Archives of Pathology and Laboratory Medicine, vol. 132, no. 6, pp. 931-939, 2008.

[6] T. Yamashita, R. Wada, T. Sasaki et al., "A vital role for glycosphingolipid synthesis during development and differentiation," Proceedings of the National Academy of Sciences of the United States of America, vol. 96, no. 16, pp. 9142-9147, 1999.

[7] A. M. Vazquez, M. Alfonso, B. Lanne et al., "Generation of a murine monoclonal antibody specific for $\mathrm{N}$-glycolylneuraminic acid-containing gangliosides that also recognizes sulfated glycolipids," Hybridoma, vol. 14, no. 6, pp. 551-556, 1995.

[8] A. Carr, A. Mullet, Z. Mazorra et al., "A mouse IgG1 monoclonal antibody specific for N-glycolyl GM3 ganglioside recognized breast and melanoma tumors," Hybridoma, vol. 19, no. 3, pp. 241-247, 2000.

[9] M. Osorio, E. Gracia, E. Rodríguez et al., "Heterophilic NeuGcGM3 ganglioside cancer vaccine in advanced melanoma patients: results of a phase Ib/IIa study," Cancer Biology and Therapy, vol. 7, no. 4, pp. 488-495, 2008.

[10] R. Blanco, E. Rengifo, M. Cedeño, C. E. Rengifo, D. F. Alonso, and A. Carr, "Immunoreactivity of the 14F7 Mab raised against $\mathrm{N}$-Glycolyl GM3 ganglioside in epithelial malignant tumors from digestive system," ISRN Gastroenterology, vol. 2011, Article ID 645641, 8 pages, 2011.

[11] H. van Cruijsen, M. Ruiz, P. van der Valk, T. D. de Gruijl, and G. Giaccone, "Tissue micro array analysis of ganglioside Nglycolyl GM3 expression and signal transducer and activator of transcription (STAT)-3 activation in relation to dendritic cell infiltration and microvessel density in non-small cell lung cancer," BMC Cancer, vol. 9, article 180, 2009.

[12] A. M. Scursoni, L. Galluzzo, S. Camarero et al., "Detection of N-glycolyl GM3 ganglioside in neuroectodermal tumors by immunohistochemistry: an attractive vaccine target for aggressive pediatric cancer," Clinical and Developmental Immunology, vol. 2011, Article ID 245181, 6 pages, 2011.

[13] A. M. Scursoni, L. Galluzzo, S. Camarero et al., "Detection and characterization of $\mathrm{N}$-glycolyated gangliosides in Wilms tumor by immunohistochemistry," Pediatric and Developmental Pathology, vol. 13, no. 1, pp. 18-23, 2010.

[14] R. Blanco, E. Rengifo, C. E. Rengifo, M. Cedeño, M. Frómeta, and A. Carr, "Immunohistochemical reactivity of the 14F7 monoclonal antibody raised against N-glycolyl GM3 ganglioside in some benign and malignant skin neoplasms," ISRN Dermatology, vol. 2011, Article ID 848909, 8 pages, 2011.

[15] R. Blanco, M. Cedeño, X. Escobar et al., "Immunorecognition of the 14F7 Mab raised against N-Glycolyl GM3 ganglioside in some normal and malignant tissues from genitourinary system," ISRN Pathology, vol. 2011, Article ID 953803, 10 pages, 2011.

[16] R. Blanco, C. E. Rengifo, M. Cedeño, M. Frómeta, E. Rengifo, and A. Carr, "Immunoreactivity of the 14F7 MAb (raised against $\mathrm{N}$-glycolyl GM3 ganglioside) as a positive prognostic factor in non-small cell lung cancer," Pathology Research International, vol. 2012, Article ID 235418, 12 pages, 2012.

[17] R. Blanco, Y. Quintana, D. Blanco et al., "Tissue reactivity of the 14F7 MAb raised against N-glycolyl GM3 ganglioside in tumors of neuroectodermal, mesodermal and epithelial origin," Journal of Biomarkers Journal of Biomarkers, vol. 2013, Article ID 602417, 9 pages, 2013.

[18] Y. Zhong, Y. Wu, C. Li et al., "N-Glycolyl GM3 ganglioside immunoexpression in oral mucosal melanomas of Chinese," Oral Diseases, vol. 18, no. 8, pp. 741-747, 2012.

[19] A. M. Vázquez, A. Pérez, A. M. Hernández et al., "Syngeneic anti-idiotypic monoclonal antibodies to an anti-NeuGccontaining ganglioside monoclonal antibody," Hybridoma, vol. 17, no. 6, pp. 527-534, 1998.

[20] L. Roque-Navarro, K. Chakrabandhu, J. de León et al., "Antiganglioside antibody-induced tumor cell death by loss of membrane integrity," Molecular Cancer Therapeutics, vol. 7, no. 7, pp. 2033-2041, 2008.

[21] A. Schwarz and A. H. Futerman, "Determination of the localization of gangliosides using anti-ganglioside antibodies: comparison of fixation methods," Journal of Histochemistry and Cytochemistry, vol. 45, no. 4, pp. 611-618, 1997.

[22] D. F. Alonso, "A novel hydrophobized GM3 ganglioside/Neisseria meningitidis outer-membrane-protein complex vaccine induces tumor protection in B16 murine melanoma," International Journal of Oncology, vol. 15, no. 1, pp. 59-66, 1999.

[23] N. Hayashi, H. Chiba, K. Kuronuma et al., "Detection of Nglycolyated gangliosides in non-small-cell lung cancer using GMR8 monoclonal antibody," Cancer Science, vol. 104, no. 1, pp. 43-47, 2013.

[24] N. Anh-Tuan, J. Pick, A. Mod, and S. R. Hollan, "Gangliosides in acute myeloid leukaemia (AML) and non-Hodgkin's lymphoma (NHL)," European Journal of Cancer and Clinical Oncology, vol. 22, no. 8, pp. 1003-1007, 1986.

[25] K. P. O’Boyle, K. Freeman, A. Kalisiak, A. Agregado, and D. A. Scheinberg, "Patterns of ganglioside expression in B cell neoplasms," Leukemia and Lymphoma, vol. 21, no. 3-4, pp. 255266, 1996.

[26] H. Higashi, Y. Nishi, Y. Fukui et al., “Tumor-associated expression of glycosphingolipid Hanganutziu-Deicher antigen in human cancers," Gann, vol. 75, no. 11, pp. 1025-1029, 1984.

[27] Y. N. Malykh, R. Schauer, and L. Shaw, "N-glycolylneuraminic acid in human tumours," Biochimie, vol. 83, no. 7, pp. 623-634, 2001.

[28] P. Tangvoranuntakul, P. Gagneux, S. Diaz et al., "Human uptake and incorporation of an immunogenic nonhuman dietary sialic acid," Proceedings of the National Academy of Sciences of the United States of America, vol. 100, no. 21, pp. 12045-12050, 2003.

[29] M. Bardor, D. H. Nguyen, S. Diaz, and A. Varki, "Mechanism of uptake and incorporation of the non-human sialic acid N-glycolylneuraminic acid into human cells," The Journal of Biological Chemistry, vol. 280, no. 6, pp. 4228-4237, 2005.

[30] T. Nishimaki, K. Kano, and F. Milgrom, "Hanganutziu-Deicher antigen and antibody in pathologic sera and tissues," Journal of Immunology, vol. 122, no. 6, pp. 2314-2318, 1979. 
[31] H. Higashi, M. Naiki, S. Matuo, and K. Okouchi, "Antigen of "serum sickness" type of heterophile antibodies in human sera: identification as gangliosides with N-glycolylneuraminic acid," Biochemical and Biophysical Research Communications, vol. 79, no. 2, pp. 388-395, 1977.

[32] D. H. Nguyen, P. Tangvoranuntakul, and A. Varki, "Effects of natural human antibodies against a nonhuman sialic acid that metabolically incorporates into activated and malignant immune cells," Journal of Immunology, vol. 175, no. 1, pp. 228236, 2005.

[33] T. Kawai, A. Kato, H. Higashi, S. Kato, and M. Naiki, "Quantitative determination of $\mathrm{N}$-glycolylneuraminic acid expression in human cancerous tissues and avian lymphoma cell lines as a tumor-associated sialic acid by gas chromatography-mass spectrometry," Cancer Research, vol. 51, no. 4, pp. 1242-1246, 1991.

[34] E. G. Kanduma, J. C. Mukuria, and O. W. Mwanda, "Serum total sialic acid and Hanganutziu-Deicher antibody in normals and in cancer patients," East African Medical Journal, vol. 84, no. 5, pp. 207-214, 2007.

[35] A. Carr, E. Rodríguez, M. D. C. Arango et al., "Immunotherapy of advanced breast cancer with a heterophilic ganglioside (NeuGcGM3) cancer vaccine," Journal of Clinical Oncology, vol. 21, no. 6, pp. 1015-1021, 2003.

[36] M. Osorio, E. Gracia, E. Reigosa et al., "Effect of vaccination with N-glycolyl GM3/VSSP vaccine by subcutaneous injection in patients with advanced cutaneous melanoma," Cancer Management and Research, vol. 4, pp. 341-345, 2012.

[37] K. Pérez, M. Osorio, J. Hernández, A. Carr, and L. E. Fernández, "NGcGM3/VSSP vaccine as treatment for melanoma patients," Human vaccines and immunotherapeutics, vol. 9, no. 6, pp. 12371240, 2013.

[38] G. Lauc and M. Heffer-Lauc, "Shedding and uptake of gangliosides and glycosylphosphatidylinositol-anchored proteins," Biochimica et Biophysica Acta, vol. 1760, no. 4, pp. 584-602, 2006.

[39] R. McKallip, R. Li, and S. Ladisch, "Tumor gangliosides inhibit the tumor-specific immune response," Journal of Immunology, vol. 163, no. 7, pp. 3718-3726, 1999.

[40] S. Birklé, G. Zeng, L. Gao, R. K. Yu, and J. Aubry, "Role of tumorassociated gangliosides in cancer progression," Biochimie, vol. 85, no. 3-4, pp. 455-463, 2003.

[41] J. de León, A. Fernández, M. Clavell et al., "Differential influence of the tumour-specific non-human sialic acid containing GM3 ganglioside on $\mathrm{CD} 4^{+} \mathrm{CD} 25^{-}$effector and naturally occurring $\mathrm{CD} 4{ }^{+} \mathrm{CD} 25^{+}$regulatory $\mathrm{T}$ cells function," International Immunology, vol. 20, no. 4, pp. 591-600, 2008.

[42] A. J. Cochran, R. Huang, J. Lee, E. Itakura, S. P. L. Leong, and R. Essner, "Tumour-induced immune modulation of sentinel lymph nodes," Nature Reviews Immunology, vol. 6, no. 9, pp. 659-670, 2006.

[43] A. Carr, C. Mesa, M. D. C. Arango, A. M. Vázquez, and L. E. Fernández, "In vivo and in vitro anti-tumor effect of 14F7 monoclonal antibody," Hybridoma and Hybridomics, vol. 21, no. 6, pp. 463-468, 2002.

[44] A. Zhiqiang, "Antibody Therapeutics-a mini review," Trends in Bio/Pharmaceutical Industry, vol. 2, pp. 24-29, 2008.

[45] Y. Fernández-Marrero, L. Roque-Navarro, T. Hernández et al., "A cytotoxic humanized anti-ganglioside antibody produced in a murine cell line defective of N-glycolylated-glycoconjugates," Immunobiology, vol. 16, no. 12, pp. 1239-12347, 2001. 


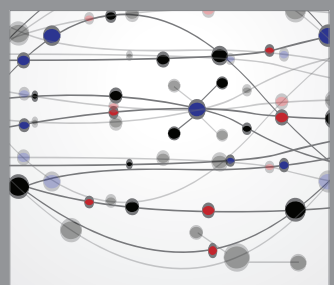

The Scientific World Journal
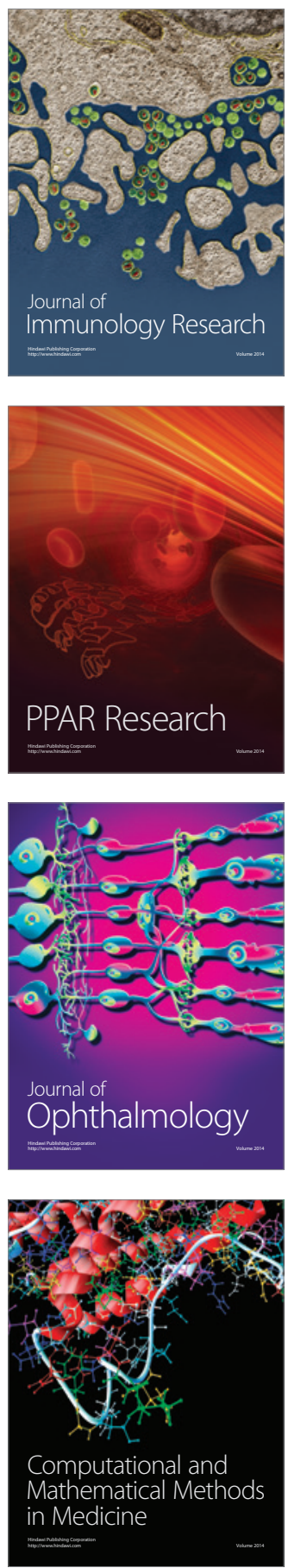

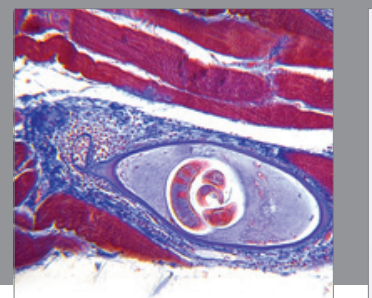

Gastroenterology

Research and Practice
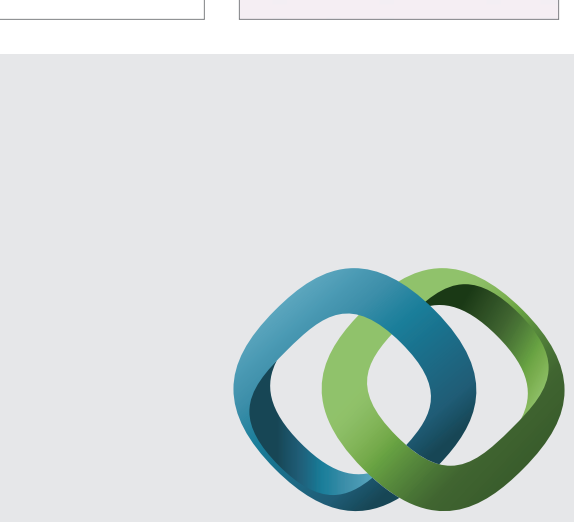

\section{Hindawi}

Submit your manuscripts at

http://www.hindawi.com
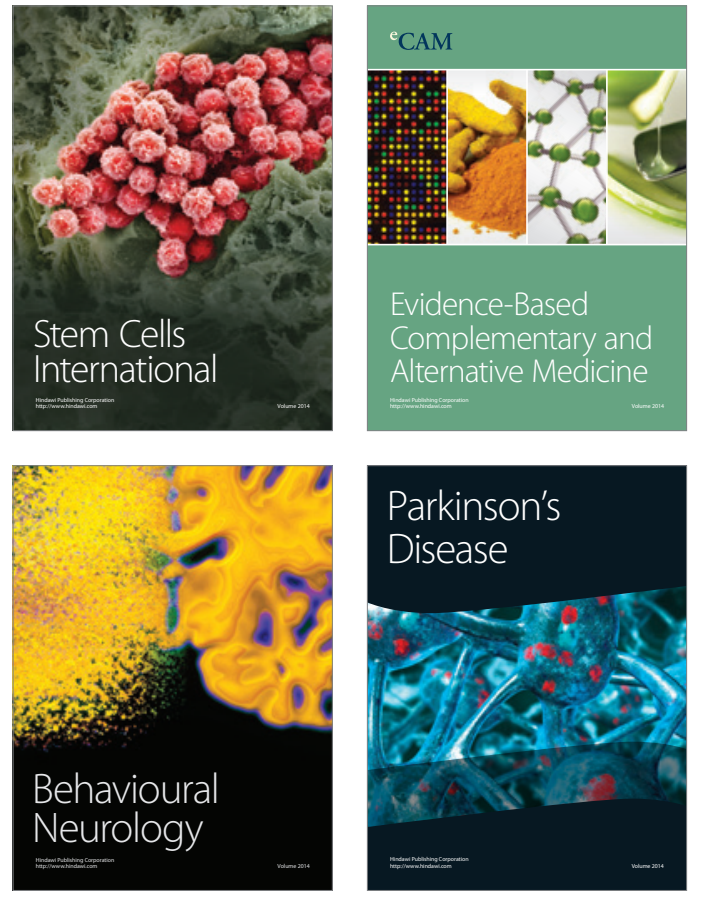
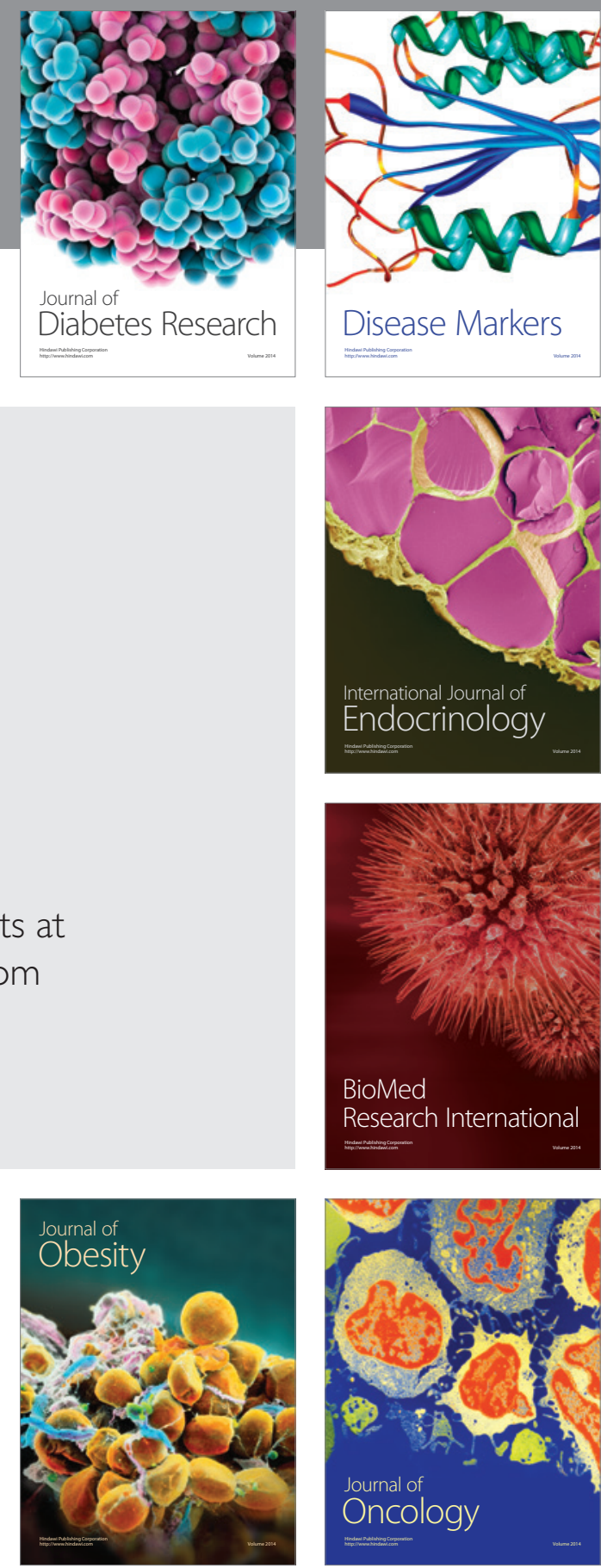

Disease Markers
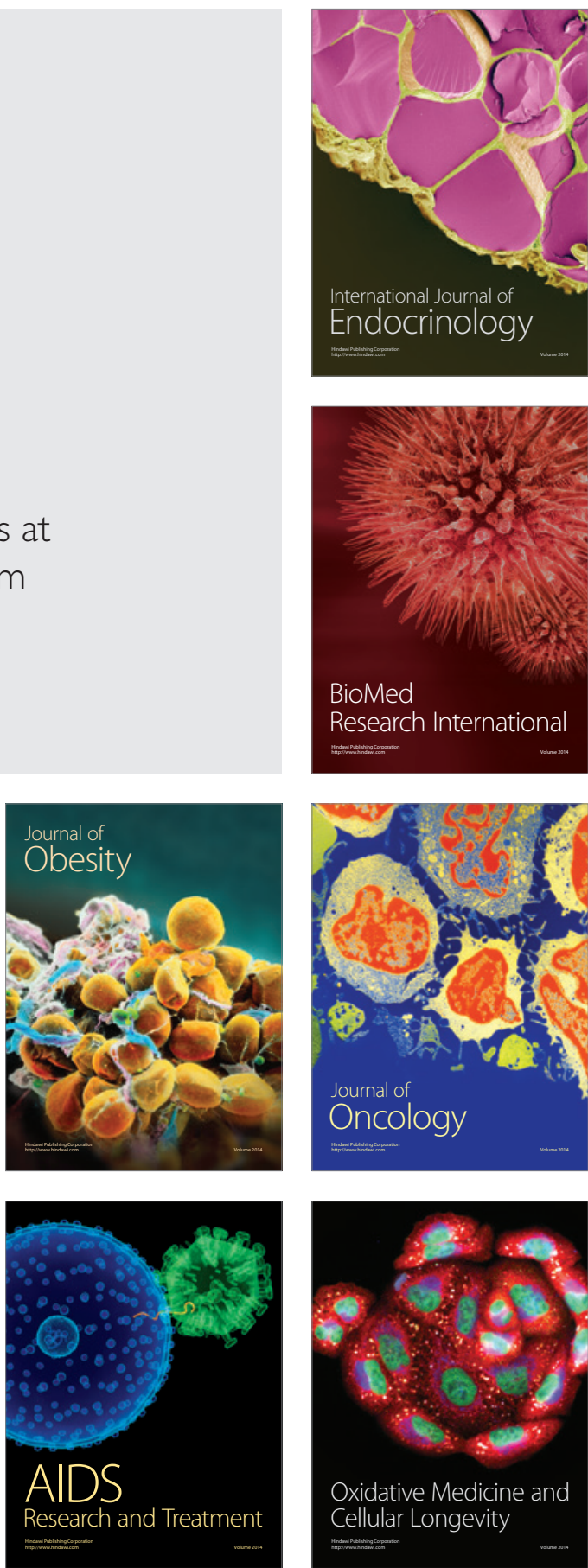